\title{
Pengukuran Tingkat Konsentrasi Para Peserta Didik Untuk Meningkatkan Efektivitas Kegiatan Pendidikan di Institusi Pendidikan Kemiliteran ' $X$ '
}

\author{
Herman R. Soetisna, Devi Tania \\ Laboratorium Rekayasa Sistem Kerja dan Ergonomi, \\ Fakultas Teknologi Industri, Institut Teknologi Bandung \\ Ganesa 10 Bandung \\ Email: hermanrs2004@gmail.com
}

\begin{abstract}
ABSTRAK
Dalam melakukan aktivitasnya, manusia kerap kali mengalami kelelahan baik fisik maupun mental. Fenomena kelelahan ini ditemukan pula pada lingkungan militer, termasuk pada sebuah institusi pendidikan kemiliteran. Penelitian ini dilakukan dengan tujuan untuk mendapatkan peta tingkat konsentrasi peserta didik dalam melakukan aktivitasnya dan inventarisasi faktor-faktor yang diduga mempengaruhinya. Sejumlah 54 peserta didik pada sebuah institusi pendidikan kemiliteran berpartisipasi dalam penelitian ini. Responden berasal dari tiga tingkat (angkatan) dan lima departemen yang berbeda. Tingkat konsentrasi per jam aktivitas (pk 05.00 s.d. 22.00 WIB) diukur dari hari Senin s.d. Jumat menggunakan perangkat lunak yang khusus dibuat untuk penelitian ini. Variabel yang diteliti adalah Reaction Time for Correct Answer (RTCA) yaitu jumlah waktu reaksi dalam menjawab dengan benar dibagi dengan jumlah jawaban benar. Aktivitas per jam juga dicatat untuk melihat bagaimana nilai RTCA berkaitan dengan kegiatan yang dilakukan. Hasil penelitian menunjukkan bahwa RTCA pada hari Selasa lebih tinggi secara signifikan dibandingkan dengan hari-hari lainnya. Pada pembandingan ratarata RTCA antar-angkatan dapat disimpulkan bahwa RTCA rata-rata tingkat II dan III lebih tinggi secara signifikan dibandingkan dengan tingkat IV, tetapi tidak terdapat perbedaan yang signifikan antara tingkat II dan III. Pada pembandingan RTCA rata-rata berdasarkan departemen, ditemukan bahwa RTCA rata-rata Departemen 1 lebih rendah secara signifikan daripada Departemen 2,3, dan 5, dan RTCA rata-rata Departemen 2 lebih tinggi secara signifikan daripada Departemen 3,4, dan 5, tetapi tidak terdapat perbedaan yang signifikan antara Departemen 1 dan 4, 3 dan 4, 3 dan 5, serta 4 dan 5. Implikasi dari hasil penelitian dibahas dalam bagian diskusi.
\end{abstract}

Kata kunci: konsentrasi, militer, stroop test, waktu reaksi

\section{PENDAHULUAN}

Dalam melakukan aktivitas, manusia menggunakan kemampuan yang dimilikinya untuk mencapai suatu tujuan tertentu. Menurut The Healthy Ageing across the Life Course (n.d.), kemampuan manusia dapat dibagi menjadi dua bagian, yaitu kemampuan fisik dan kognitif. Kemampuan fisik berkaitan dengan kapasitas individu untuk melakukan tugas-tugas fisik (physical tasks) yang diperlukan sehari-hari, sedangkan kemampuan kognitif berkaitan dengan kapasitas individu untuk melakukan tugas-tugas mental (mental tasks). Sementara itu, tidak dapat dipungkiri bahwa manusia juga memiliki keterbatasan. Dalam melakukan aktivitasnya manusia kerap kali mengalami kelelahan. Kelelahan merupakan suatu tanda yang menunjukkan bahwa manusia pada dasarnya memiliki keterbatasan. Menurut Bartley dan Chute (1947, dalam Olson, 2007), kelelahan dipercaya sebagai sinyal awal bahwa kegiatan seseorang telah melebihi kapasitasnya. Selain itu, kelelahan dapat menyebabkan melambatnya reaksi, berkurangnya kemampuan untuk memroses informasi, penyimpangan memori, linglung, dan berkurangnya kesadaran (Health and Safety Executive, 2015).

Secara garis besar, kelelahan merupakan suatu pola yang timbul pada suatu keadaan, yang secara umum terjadi pada setiap individu yang sudah tidak sanggup lagi melakukan aktivitasnya (Sutalaksana et al., 2006). Pada dasarnya kelelahan ditimbulkan oleh dua hal, yaitu kelelahan fisiologis (fisik atau kimia) dan psikologis (mental atau fungsional). Kelelahan fisiologis adalah kelelahan yang timbul karena adanya perubahan-perubahan faali dalam tubuh, yaitu menumpuknya asam laktat dalam otot dan peredaran darah yang dapat menghambat gerakan otot dan membatasi kelangsungan aktivitas otot yang bersangkutan, sedangkan kelelahan psikologis timbul dalam 
perasaan pekerja yang dapat disebabkan oleh kurangnya minat dalam melakukan aktivitas, aktivitas yang monoton, keadaan lingkungan, atau berbagai penyakit [ibid].

Sutalaksana et al. (2006) memaparkan suatu daftar yang dapat dijadikan sebagai patokan untuk mengetahui datangnya gejala-gejala perasaan kelelahan dan terbagi ke dalam tiga kelompok, yaitu kelompok perlemahan kegiatan, perlemahan motivasi, dan kelelahan fisik akibat psikologis. Pada kelompok perlemahan kegiatan, gejala kelelahan yang timbul adalah kepala terasa berat, lelah seluruh badan, mengantuk, dan merasa ingin berbaring. Pada kelompok perlemahan motivasi, gejala kelelahan yang timbul adalah merasa susah berpikir, tidak dapat berkonsentrasi, tidak dapat memusatkan perhatian terhadap sesuatu pada kelompok kelelahan fisik akibat psikologis, gejala kelelahan yang timbul adalah sakit kepala, kekakuan bahu, pernapasan merasa tertekan, merasa kurang sehat badan.

Berdasarkan daftar tersebut, salah satu gejala kelelahan adalah mengantuk/kantuk. Menurut National Institute of Health (1997), kantuk dapat disebabkan oleh siklus bangun-tidur tubuh sehari-hari secara alamiah, kurang tidur, penyakit, atau obat-obatan tertentu. Gejala kantuk ini ditemukan pada lingkungan militer, khususnya pendidikan kemiliteran. Institusi pendidikan kemiliteran ' $\mathrm{X}$ ' merupakan salah satu lembaga yang bertugas untuk mendidik para peserta didik untuk menjadi prajurit dengan metode pengajaran, pelatihan, dan pengasuhan. Peserta didik di dalamnya menjalani pelatihan secara fisik (olahraga, bela diri, dan kegiatan fisik lainnya) dan secara akademik di kelas.

Berdasarkan hasil diskusi dengan pengajar dan manajemen institusi, kondisi aktual yang terjadi adalah beberapa peserta didik sering ditemukan mengantuk saat kegiatan belajar di kelas, termasuk pada pagi hari, padahal sebelumnya mereka sudah berolahraga. Hal ini mengakibatkan proses belajar-mengajar tidak dapat berjalan secara efektif karena peserta didik tersebut tidak dapat memusatkan perhatian selama kegiatan di kelas berlangsung. Perilaku mengantuk ini juga ditemukan saat observasi awal dilakukan, di mana beberapa peserta didik terlihat tidak dapat memusatkan perhatian saat kegiatan belajar berlangsung.

Salah satu gejala kelelahan lainnya menurut Sutalaksana et al. (2006) adalah tidak dapat berkonsentrasi. Kelelahan baik fisik maupun mental dapat memengaruhi tingkat konsentrasi seseorang. Untuk mengetahui bagaimana aktivitas yang dilakukan sehari-hari memengaruhi tingkat konsentrasi, perlu dilakukan pemetaan tentang konsentrasi peserta didik dalam melakukan aktivitasnya. Tingkat konsentrasi seseorang dapat diukur dengan menggunakan Stroop test. Stroop test memanfaatkan operasi primitif kognisi, menawarkan petunjuk untuk proses dasar atensi (MacLeod, 1991). Dalam tes ini responden harus menamakan warna dari kata yang tidak sinkron dengan pembacaan katanya, misalnya respon "biru" untuk kata kuning yang dicetak berwarna biru. Stroop test sangat terkenal karena memiliki pengaruh yang besar dan selalu secara statistik dapat diandalkan (MacLeod, 1992). Penelitian ini dilakukan untuk memetakan tingkat konsentrasi didik dalam melakukan aktivitas sehari-hari dan mengidentifikasi faktor-faktor yang memengaruhinya.

\section{METODE}

\section{Responden}

Responden dalam penelitian ini adalah 54 peserta didik (51 laki-laki dan 3 perempuan) berasal dari tingkat (angkatan) yang berbeda yaitu tingkat II, III, dan IV serta lima departemen (jurusan) yang berbeda yaitu 1,2,3,4, dan 5. Responden dipilih menggunakan stratified sampling berdasarkan strata kinerja peserta didik yang menjadi catatan akademik dalam institusi di mana kinerja mereka dibagi ke dalam strata rendah, sedang, dan tinggi.

Prosedur

Pengukuran dilakukan menggunakan stroop test dengan kata-kata netral, yaitu merah, biru, hijau, dan kuning. Instruksi yang diberikan kepada responden adalah mengetik huruf inisial dari warna kata yang ditampilkan. Sebagai contoh, untuk kata 'MERAH' yang ditampilkan dalam warna hijau, jawaban yang diharapkan adalah 'H'. Proses pengumpulan data dibantu oleh 15 orang pengukur dari pihak institusi yang kemudian diberikan pengarahan tentang cara mengoperasikan perangkat lunak stroop test dan mencoba mengerjakan tes. Untuk mengakomodasi proses belajar responden, uji coba pengukuran dilakukan dengan mengumpulkan pengukur dan responden ke dalam satu ruangan dan pengukur memberikan arahan kepada responden tentang pengerjaan tes. Pengukuran sesungguhnya dilakukan setiap jam dari pk 05.00 s.d. pk 22.00 WIB selama lima hari (Senin-Jumat). Khusus untuk hari Rabu, pengukuran untuk tingkat III dan IV hanya dilakukan sampai pk 16.00 karena terdapat kegiatan pesiar. 
Pengukuran dilakukan segera setelah kegiatan dilakukan atau di tengah-tengah kegiatan yang dijalankan. Aktivitas sehari-hari yang dijalankan oleh masing-masing tingkatan dan departemen bisa berbeda sehingga peserta didik sulit dikumpulkan ke dalam satu tempat. Untuk mengatasi kendala ini, pada pengukuran sesungguhnya pengukur datang ke tempat responden supaya hasil pengukuran tidak bias. Selain itu, aktivitas yang dilakukan saat pengukuran juga dicatat.

Data yang dikumpulkan adalah Reaction Time for Correct Answer (RTCA), yaitu jumlah waktu reaksi untuk menjawab dengan benar dibagi dengan jumlah jawaban benar. RTCA yang rendah menandakan tingkat konsentrasi yang tinggi, sebaliknya, RTCA yang tinggi menandakan tingkat konsentrasi yang rendah. Data RTCA diolah menggunakan perangkat lunak SPSS (versi 16.0; SPSS Inc., Chicago, IL, USA) dan kemudian dianalisis. $\underline{\text { Alat }}$

Pengukuran dilakukan menggunakan perangkat lunak stroop test yang terinstalasi dalam laptop pada saat pengumpulan data. Terdapat 15 buah laptop yang disediakan oleh institusi untuk mengakomodasi pengukuran seluruh tingkat dan departemen. Jenis stroop test yang digunakan pada penelitian ini adalah original stroop test di mana kata-kata yang digunakan adalah kata-kata netral yaitu merah, biru, hijau, kuning.

\section{HASIL DAN PEMBAHASAN}

Penyajian data dibagi ke dalam beberapa bentuk yaitu untuk RTCA rata-rata seluruh peserta didik berdasarkan hari, RTCA rata-rata responden berdasarkan tingkat, dan berdasarkan departemen. Dalam penelitian ini, pembandingan dilakukan untuk pengukuran tingkat konsentrasi dalam melakukan aktivitas seluruh peserta didik per hari, perbandingan antartingkat, dan perbandingan antardepartemen. RTCA Rata-rata Seluruh Responden dapat dilihat pada Gambar 1.

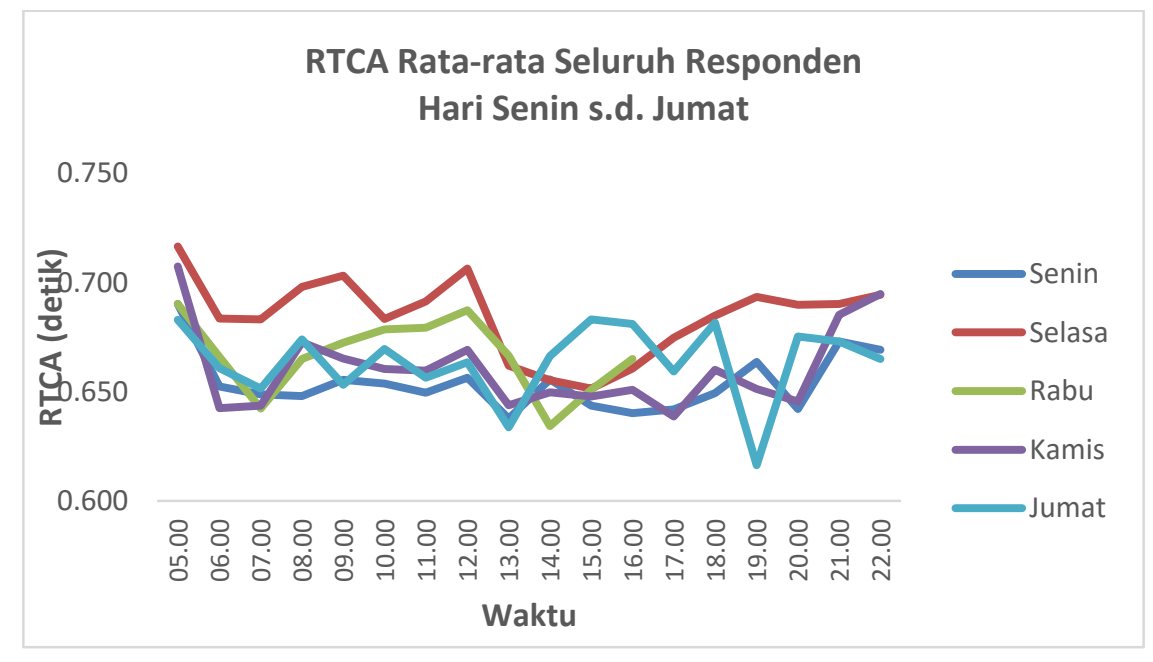

Gambar 1 - RTCA Rata-rata Seluruh Responden Hari Senin s.d. Jumat

RTCA rata-rata maksimum diperoleh pada hari Selasa pk 05.00 WIB sebesar 0.717 detik. Dari fenomena ini, muncul dugaan tentang terjadinya aktivitas pada malam sebelumnya (Senin malam) yang menyebabkan para peserta didik tidak dapat beristirahat dengan cukup. Menurut penelitian terdahulu, kurang tidur jangka pendek (pada malam sebelumnya) dapat mempengaruhi fungsi kognitif seperti waktu reaksi di pagi hari (Taheri, 2012). Untuk mengetahui seberapa signifikan perbedaan RTCA rata-rata per harinya, ANOVA satu jalur dilakukan dan diperoleh $\mathrm{p}=0.000(\alpha=0.05)$ yang mengindikasikan terdapat perbedaan yang signifikan antara RTCA rata-rata hari Senin, Selasa, Rabu, Kamis, dan Jumat. Untuk mengetahui pada hari manakah perbedaan yang signifikan ditemukan, uji Post Hoc Tukey dilakukan dan ditemukan hasil sebagaimana dapat dilihat pada Tabel 1.

Tabel 1 - Rekapitulasi Uji Post Hoc Tukey RTCA Rata-rata Seluruh Responden Per Hari

\begin{tabular}{ccccc}
\hline \multicolumn{2}{l}{ Perbandingan (Hari) } & Nilai Signifikansi (p) & Kesimpulan & Keterangan \\
\hline Senin & Selasa & 0.000 & berbeda signifikan & RTCA Selasa $>$ Senin \\
\hline Selasa & Rabu & 0.044 & berbeda signifikan & RTCA Selasa $>$ Rabu \\
\hline
\end{tabular}




\begin{tabular}{|c|c|c|c|c|}
\hline Selasa & Kamis & 0.001 & berbeda signifikan & RTCA Selasa > Kamis \\
\hline Selasa & Jumat & 0.004 & berbeda signifikan & RTCA Selasa > Jumat \\
\hline
\end{tabular}

Dari Tabel 1 ditemukan bahwa terdapat perbedaan yang signifikan antara RTCA rata-rata hari Selasa dibandingkan dengan hari lainnya ( $\mathrm{p}=0.000$ untuk hari Senin dan Selasa, $\mathrm{p}=0.044$ untuk Selasa dan Rabu, $\mathrm{p}=0.001$ untuk hari Selasa dan Kamis, dan p=0.004 untuk hari Selasa dan Jumat). Hasil uji ini mengindikasikan terdapat beban aktivitas yang berlebih pada hari Selasa dibandingkan dengan hari lainnya yang mempengaruhi RTCA.

Salah satu rangkaian kegiatan yang harus dilakukan pada hari Selasa adalah latihan drumband. Menurut hasil diskusi dengan pihak pengurus institusi $\mathrm{X}$, latihan drumband ini tergolong kegiatan yang lebih melelahkan dibandingkan kegiatan-kegiatan luar kelas lainnya. Para peserta didik harus berada di lapangan terbuka dengan panas terik matahari selama 3 jam (pk 14.00 s.d. pk 17.00 WIB) dengan membawa peralatan musik dan pelatihan baris-berbaris. Kegiatan ini patut diduga menjadi salah satu faktor yang menyebabkan tingginya RTCA rata-rata hari Selasa dibandingkan hari lainnya. Hal ini terlihat pada Gambar 1 grafik RTCA rata-rata pada pk 14.00 s.d. pk 19.00 WIB hari Selasa memiliki tren naik.

Setelah berdiskusi dengan pihak pengurus institusi, pengasuh yang bertugas untuk menjaga malam di mess tempat para peserta didik beristirahat diduga mempengaruhi jam tidur. Salah satu peran pengasuh adalah memastikan para peserta didik agar tidur sesuai jadwal, namun pada kenyataannya pengasuh yang berbeda dapat memberikan perlakuan yang berbeda pula (bersifat ketat atau memberikan kelonggaran terhadap pelaksanaan jam tidur). Dari temuan yang didapatkan, muncul dugaan bahwa terdapat perbedaan "perlakuan" pengasuh Senin malamnya yang membuat peserta didik tidak dapat beristirahat dengan cukup.

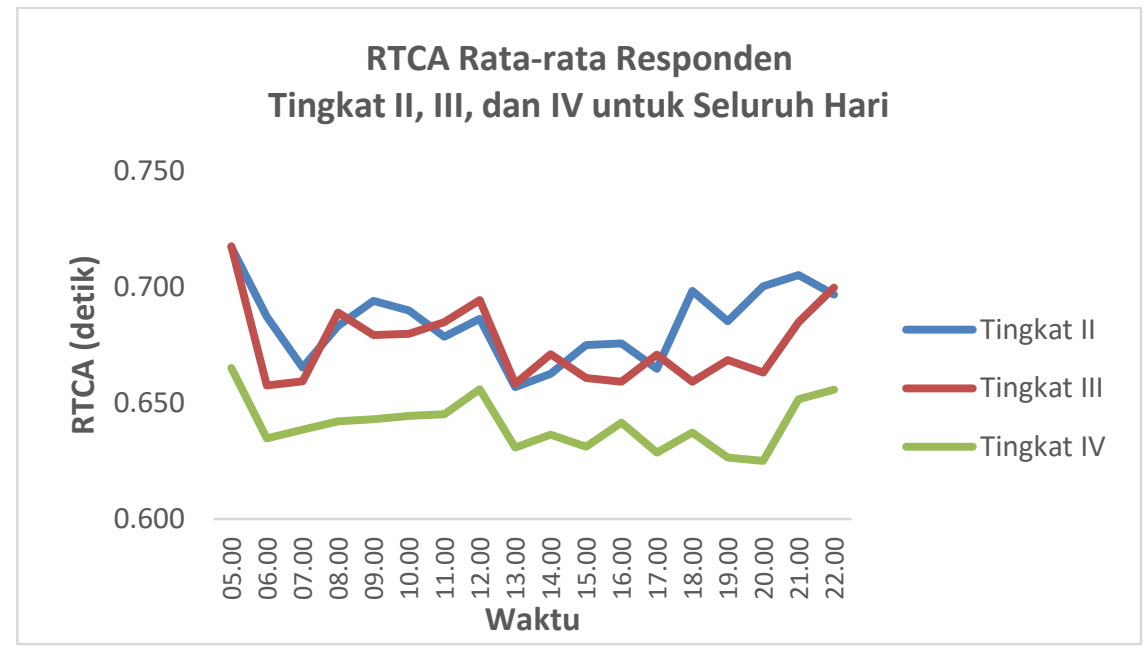

Gambar 2 RTCA Rata-rata Responden Tingkat II, III, dan IV untuk Seluruh Hari

Gambar 2 menunjukkan RTCA Rata-rata Responden Tingkat II, III, dan IV untuk Seluruh Hari. RTCA rata-rata maksimum diperoleh pada pk 05.00 WIB oleh tingkat III sebesar 0.718 detik. Nilai ini tidak berbeda jauh dengan nilai RTCA rata-rata tingkat II yaitu 0.717 detik. Hal ini menunjukkan bahwa secara umum waktu reaksi paling tinggi adalah saat bangun pagi. Hal ini dapat disebabkan oleh kurangnya durasi tidur para responden pada malam sebelumnya.

RTCA rata-rata minimum diperoleh pada pk 20.00 WIB pada tingkat IV yaitu sebesar 0,625 detik. Aktivitas yang dilakukan pada jam tersebut adalah belajar mandiri dan kegiatan belajar tersebut dilakukan 1 jam sesudah makan malam. Pada waktu ini diduga makan malam menyebabkan menurunnya waktu reaksi. Dugaan ini didukung oleh penelitian Angus Craig dan D. Phil (1986) yang menemukan bahwa asupan makan menyebabkan peningkatan kinerja satu jam setelah makan.

ANOVA satu jalur dilakukan dan diperoleh $\mathrm{p}=0.000$ yang mengindikasikan terdapat perbedaan yang signifikan antara RTCA rata-rata tingkat II, III, dan IV. Untuk mengidentifikasi pada tingkat mana persis perbedaan yang signifikan terjadi, dilakukan uji Post Hoc Tukey dengan hasil pada Tabel 2 berikut. 
Tabel 2 - Rekapitulasi Uji Post Hoc Tukey RTCA Antartingkat

\begin{tabular}{cccccc}
\hline No. & $\begin{array}{c}\text { Perbandingan } \\
\text { RTCA (Tingkat) }\end{array}$ & $\begin{array}{c}\text { Nilai } \\
\text { Signifikansi } \\
(\mathbf{p})\end{array}$ & Kesimpulan & Keterangan \\
\hline 1 & II & IV & 0.000 & berbeda signifikan & Tingkat II > IV \\
\hline 2 & III & IV & 0.000 & berbeda signifikan & Tingkat III > IV \\
\hline
\end{tabular}

Dari Gambar 2 terlihat bahwa grafik RTCA rata-rata tingkat IV lebih rendah dibandingkan dengan kedua tingkat lainnya. Dari Tabel 2 diperoleh informasi bahwa perbedaan yang signifikan ditemukan antara RTCA rata-rata tingkat II dengan IV ( $\mathrm{p}=0.000)$, dan tingkat III dengan IV $(\mathrm{p}=0.000)$, tetapi tidak terdapat perbedaan yang signifikan antara RTCA tingkat II dengan III $(\mathrm{p}=0.172)$. Perbedaan ini dapat disebabkan oleh berbagai hal. Secara fisik, tingkat II dan III harus melakukan tugas-tugas tambahan yang tidak dilakukan oleh tingkat IV ketika jam akademik berakhir berupa aktivitas-aktivitas fisik yang diberikan setiap hari oleh para peserta didik tingkat IV sebagai "angkatan senior" yang bertugas untuk mendidik junior-juniornya, dengan kondisi peserta didik dari berbagai angkatan tidur di dalam satu kamar yang sama di gedung asrama. Kegiatan ini diduga membuat para peserta didik tingkat II dan III tidak dapat beristirahat dengan cukup karena tugas tersebut harus langsung dikerjakan dan diselesaikan ketika diberikan dan menyebabkan kelelahan yang lebih tinggi dibandingkan dengan peserta didik tingkat IV sehingga waktu reaksi mereka lebih lambat.

Selain itu, berdasarkan aktivitas harian, peserta didik tingkat II harus melakukan lari siang hampir setiap hari yang tidak selalu dilakukan oleh peserta didik tingkat III dan IV. Lari siang ini dilakukan ketika peserta didik tingkat IV sedang berada di kelas. Perbedaan kegiatan yang dilakukan ini diduga membuat para peserta tingkat II lebih lelah dibandingkan peserta didik tingkat IV sehingga RTCA mereka pun lebih tinggi dibandingkan dengan peserta didik tingkat IV.

Penyebab lain yang diduga memengaruhi perbedaan RTCA rata-rata antartingkat ini adalah tentang asupan makanan yang berbeda antara peserta didik. Berdasarkan diskusi dengan pengurus, seluruh peserta didik seharusnya mendapatkan makanan ringan pada pk 09.30, namun pada kenyataannya peserta didik tingkat II tidak memanfaatkan kesempatan itu mengingat tempat pengambilan makanan ringan dilakukan di tempat yang sama dengan tingkat III dan IV. Dari pembicaraan dengan beberapa pihak, ini terjadi karena mereka "segan" kepada para seniornya.

1) RTCA Rata-rata Responden Departemen 1,2,3,4, dan 5 untuk Seluruh Hari

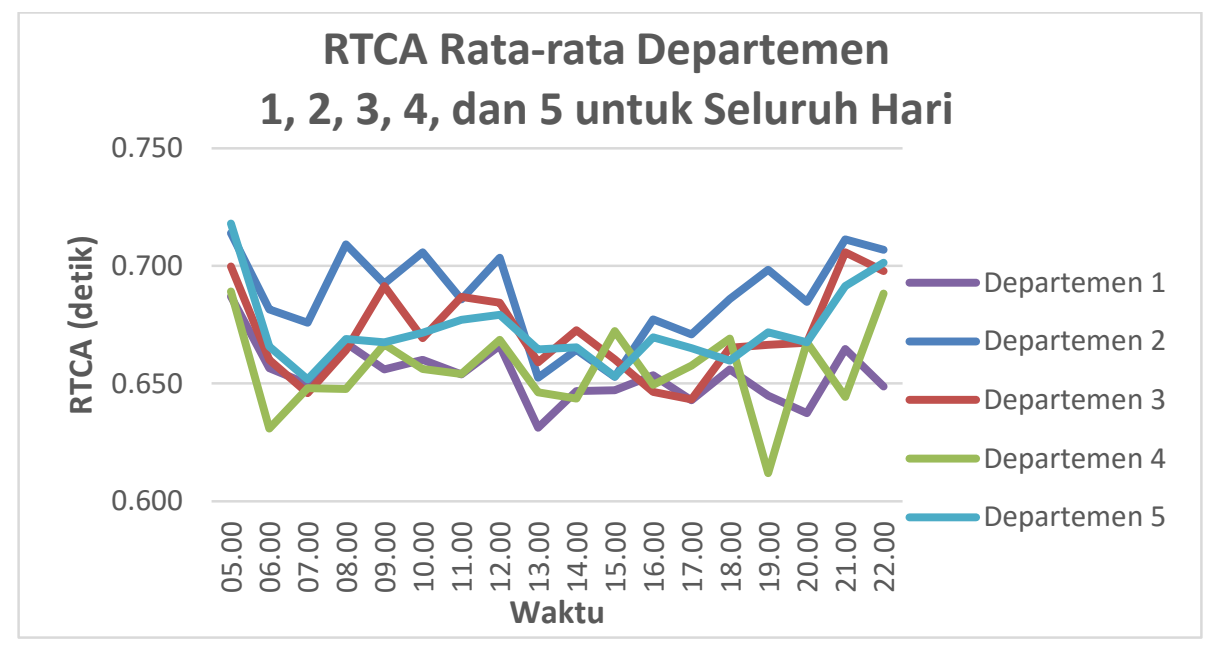

Gambar 3 - RTCA Rata-rata Responden Departemen 1,2,3,4, dan 5 untuk Seluruh Hari

RTCA rata-rata maksimum diperoleh oleh departemen 2 pada pk 05.00 yaitu sebesar 0.718 detik. Berdasarkan data aktivitas harian, pada pk 05.00 WIB merupakan waktu bangun pagi dan persiapan untuk lari pagi. Fenomena ini dialami oleh seluruh departemen secara umum di mana terlihat pada Gambar 3 bahwa pada pk 05.00 WIB 
RTCA rata-rata yang diperoleh tinggi kemudian menurun tajam pada pk $06.00 \mathrm{WIB}$ yaitu pengukuran sesudah lari pagi.

RTCA rata-rata minimum diperoleh oleh departemen 4 pada pk 19.00 yaitu sebesar 0.612 detik. Berdasarkan data aktivitas harian, waktu tersebut merupakan makan malam dan diduga makan malam membuat responden lebih tanggap dalam menjawab tes.

Untuk mengetahui apakah terdapat perbedaan yang signifikan antara nilai RTCA rata-rata antardepartemen, ANOVA satu jalur dilakukan dan diperoleh nilai $\mathrm{p}=0.000$ yang berarti bahwa terdapat perbedaan yang signifikan antara nilai RTCA rata-rata antardepartemen. Untuk mengetahui pada departemen manakah perbedaan yang signifikan ditemukan, uji Post Hoc Tukey dilakukan dan ditemukan hasil pada Tabel 3 sebagai berikut.

Tabel 3 - Rekapitulasi Uji Post Hoc Tukey RTCA Rata-rata Antardepartemen

\begin{tabular}{cccccc}
\hline No. & $\begin{array}{c}\text { Perbandingan RTCA } \\
\text { (Departemen) }\end{array}$ & $\begin{array}{c}\text { Nilai Sig. } \\
(\mathbf{p})\end{array}$ & Kesimpulan & Keterangan \\
\hline 1 & Dept 1 & Dept 2 & 0,000 & berbeda signifikan & RTCA Dept $1<$ Dept 2 \\
\hline 2 & Dept 1 & Dept 3 & 0,023 & berbeda signifikan & RTCA Dept $1<$ Dept 3 \\
\hline 3 & Dept 1 & Dept 5 & 0,027 & berbeda signifikan & RTCA Dept $1<$ Dept 5 \\
\hline 4 & Dept 2 & Dept 3 & 0,046 & berbeda signifikan & RTCA Dept $2>$ Dept 3 \\
\hline 5 & Dept 2 & Dept 4 & 0,000 & berbeda signifikan & RTCA Dept $2>$ Dept 4 \\
\hline 6 & Dept 2 & Dept 5 & 0,040 & berbeda signifikan & RTCA Dept $2>$ Dept 5 \\
\hline
\end{tabular}

Dari Tabel 3 diperoleh informasi bahwa terdapat perbedaan yang signifikan antara nilai RTCA raat-rata departemen 1 dengan 2, 1 dengan 3, 1 dengan 5, 2 dengan 3, 2 dengan 4, 2 dengan 5, 3 dengan 4, dan 4 dengan 5 . Tidak ditemukan perbedaan yang signifikan antara RTCA rata-rata departemen 1 dengan 4, dan 3 dengan 5. Perbedaan nilai RTCA rata-rata dari departemen ini dapat disebabkan oleh kegiatan yang tidak selalu sama untuk masing-masing departemen. Pada satu hari yang sama, peserta didik pada sebuah departemen dapat melakukan kegiatan yang berbeda dengan departemen lainnya, yaitu berenang pada pagi hari di kala departemen lainnya sedang belajar di kelas. Sebagai contoh, peserta didik tingkat IV Departemen 2 pada hari Rabu melakukan kegiatan berenang di pagi hari (pk 07.00 s.d. pk 09.00 WIB) ketika peserta didik tingkat IV departemen lainnya $(1,3,4$, dan 5) sedang belajar di kelas. Selain itu, perbedaan lain yang ditemukan adalah peserta didik tingkat IV Departemen 4 dan 5 tidak melakukan kegiatan berenang di pagi hari selama pengukuran dilakukan. Untuk peserta didik tingkat III, hanya departemen 2 dan 4 saja yang melakukan kegiatan berenang di pagi hari, tepatnya pada hari Senin untuk Departemen 4, dan Selasa untuk kedua departemen.

Berdasarkan diskusi dengan pihak pengurus, perbedaan kegiatan yang diduga mempengaruhi RTCA adalah khusus pada Departemen 5 terdapat kegiatan persiapan pelatihan fisik tambahan untuk pendidikan komando yang tidak dialami oleh peserta didik departemen lainnya setiap hari ketika ronda malam (pk 21.00 s.d. 22.00 WIB). Kegiatan ini menuntut kebutuhan fisik yang tinggi dan diduga memengaruhi waktu reaksi Departemen 5.

Dalam menerapkan rekomendasi perbaikan, Soetisna ${ }^{1}$ mengatakan sebaiknya terdapat suatu sistem yang diterapkan untuk lebih menjamin efektivitas implementasi dari suatu aturan, program dan lain-lain, yang disebut dengan Sistem 6E-1M. Sistem ini meliputi Engineering, Educating the people, Enforcing the Law, Empowering the people, Enabling the System, Engaging the Leader to the System, dan Maintenance, yang dijabarkan sebagai berikut.

1. Engineering

Engineering diartikan sebagai perancangan, yaitu perancangan sistem kerja yang lebih baik. Sebagai contoh, engineering dalam meningkatkan tingkat konsentrasi adalah penggunaan gedung asrama yang sama untuk peserta didik dari tingkat yang sama, penerapan aturan/SOP tentang pelaksanaan pengasuhan

1 H.R. Soetisna, "Sistem 6E-1M, Cara Holistik untuk Menjamin Efektivitas Pelaksanaan/Implementasi Program-program Perbaikan", belum dipublikasikan. 
yang seragam agar tidak terjadi perbedaan perlakuan antar-pengasuh, dan perubahan metode pemberian makanan ringan (snack) kepada peserta didik tingkat II.

2. Educating The People

Educating berarti melakukan edukasi atau sosialisasi terhadap hal-hal yang baru dirancang termasuk sanksinya.

3. Enforcing the Law

Untuk "memaksa" seluruh pihak menjalankan peraturan baru tadi, diberlakukan penegakan hukum dengan menerapkan hukuman jika ada pihak yang tidak melaksanakan aturan.

4. Empowering The People

Empowerment ini diartikan sebagai "pemberdayaan pengguna sistem" di mana mereka diberi peran peran dalam implementasi dari perancangan (fisik) dan atau peraturan/perbaikan yang baru dengan membangun suatu "Sistem Sumbang Saran" (Suggestion System)

5. Enabling the System

Enabling di sini diartikan sebagai tindakan yang dilakukan agar rancangan yang baru "di-install" tadi dapat dijalankan. Pimpinan harus selalu "menyuarakan" tentang pentingnya keberhasilan penerapan program-program yang direncanakan tadi, pada setiap kesempatan.

6. Engaging the Leader to the System

Engaging di sini diartikan sebagai keterlibatan pimpinan (puncak) dalam kegiatan-kegiatan (dan rapatrapat) yang dilakukan oleh para panitia kerja yang sedang membangun sistem yang diperlukan untuk suatu program yang direncanakan, paling tidak satu kali.

7. Maintaining the System

Maintaining di sini diartikan sebagai tindakan untuk "menjaga" agar sistem ini tetap berjalan dengan baik dengan melakukan evaluasi secara berkala terhadap rancangan-rancangan yang sudah diterapkan, cara sosialisasi dan sanksi yang dikenakan untuk para pelanggar.

\section{KESIMPULAN DAN SARAN}

Faktor-faktor yang diduga menyebabkan perbedaan tingkat kelelahan pada Institusi pendidikan militer X adalah perbedaan kegiatan per harinya, perbedaan "perlakuan" antarpengasuh yang berbeda saat pelaksanaan istirahat malam, dan perbedaan aktivitas antartingkat dan departemen peserta didik dalam institusi. Rekomendasi yang diberikan adalah agar Institusi ' $\mathrm{X}$ ' melakukan kajian lebih lanjut tentang penggunaan gedung asrama, apakah lebih baik "campuran antar tingkat" pada gedung asrama yang sama (seperti keadaan saat ini), ataukah lebih baik jika gedung asrama yang sama hanya diisi oleh para peserta didik dari angkatan yang sama. Yang kedua adalah perlunya kajian tentang standardisasi pola dan aturan pengasuhan agar tidak ada perbedaan perlakuan antarpengasuh saat istirahat malam. Selain itu, diusulkan pula agar Institusi ' $X$ ' melakukan kajian tentang lokasi pemberian makanan ringan kepada peserta didik tingkat II.

\section{DAFTAR PUSTAKA}

[1]. Craig, A., \& D., P. (1986). Acute Effects of Meals on Perceptual and Cognitive Efficiency. Cognitive Function, 163-171.

[2]. Health and Safety Executive. (n.d.). Human factors: Fatigue. Retrieved February 15, 2015, from Health and Safety Executive: http://www.hse.gov.uk/humanfactors/topics/fatigue.htm

[3]. Krueger, G. P. (1989). Sustained Work, Fatigue, Sleep Loss and Performance: A Review of the Issues. Work \& Stress, 3(2), 129-141.

[4]. The Healthy Ageing across the Life Course. (n.d.). Work Packages: Physical and cognitive capability. Retrieved February 8, 2015, from The Healthy Ageing across the Life Course: http://www.halcyon.ac.uk/?q=work-packages-one

[5]. MacLeod, C. M. (1991). Half a Century of Research on the Stroop Effect: An Integrative Review. Psychological Bulletin, 109(2), 163-203.

[6]. MacLeod, C. M. (1992). The Stroop Task: The "Gold Standard" of Attentional Measures. Journal of Experimental Psychology:General, 121(1), 12-14. 
[7]. National Institute of Health. (1997). Facts about Problem Sleepiness. US: NIH Publication.

[8]. Olson, K. (2007). A new way of thinking about fatigue: a reconceptualization. Oncology Nursing Forum, 34, 93-99.

[9]. Soetisna, H.R. Sistem 6E-1M, Cara Holistik untuk Menjamin Efektivitas Pelaksanaan/Implementasi Program-program Perbaikan. Unpublished.

[10]. Sutalaksana, I. Z., Anggawisastra, R., \& Tjakraatmaja, J. (2006). Teknik Perancangan Sistem Kerja. Bandung: Penerbit ITB.

[11]. Taheri, M. \&. (2012). The Effects of Sleep Deprivation on Choice Reaction Time and Anaerobic Power of College Student Athletes. Asian Journal of Sports Medicine, 3(1), 15-20.

[12]. Workplace Safety and Health. (2010). Fatigue Management. Singapore: Workplace Safety and Health Council. 